\title{
Antibiotic Resistance, spa Typing and Clonal Analysis of Methicillin-Resistant Staphylococcus aureus (MRSA) Isolates from Blood of Patients Hospitalized in the Czech Republic
}

\author{
Katarina Pomorska ${ }^{1}$ D , Vladislav Jakubu ${ }^{1,2,3}$, Lucia Malisova ${ }^{1,3}$, Marta Fridrichova ${ }^{3}$, Martin Musilek ${ }^{4}$ (D) and \\ Helena Zemlickova ${ }^{1,2,3, * \text { (D) }}$ \\ 1 Centre for Epidemiology and Microbiology, National Reference Laboratory for Antibiotics, National Institute \\ of Public Health, 10000 Prague, Czech Republic; katarina.pomorska@szu.cz (K.P.); \\ vladislav.jakubu@szu.cz (V.J.); lucia.malisova@szu.cz (L.M.) \\ 2 Department of Clinical Microbiology, Faculty of Medicine and University Hospital, Charles University, \\ 53002 Hradec Kralove, Czech Republic \\ 3 Department of Microbiology, 3rd Faculty of Medicine Charles University, University Hospital Kralovske \\ Vinohrady, National Institute of Public Health, 10000 Prague, Czech Republic; marta.fridrichova@fnkv.cz \\ 4 Centre for Epidemiology and Microbiology, National Reference Laboratory for Meningococcal Infections, \\ National Institute of Public Health, 10000 Prague, Czech Republic; martin.musilek@szu.cz \\ * Correspondence: hzemlickova@szu.cz
}

check for updates

Citation: Pomorska, K.; Jakubu, V.; Malisova, L.; Fridrichova, M.; Musilek, M.; Zemlickova, H. Antibiotic Resistance, spa Typing and Clonal Analysis of

Methicillin-Resistant Staphylococcus aureus (MRSA) Isolates from Blood of Patients Hospitalized in the Czech Republic. Antibiotics 2021, 10, 395. https://doi.org/10.3390/ antibiotics10040395

Academic Editors: Pavel Bostik and Milan Kolar

Received: 5 March 2021

Accepted: 5 April 2021

Published: 6 April 2021

Publisher's Note: MDPI stays neutral with regard to jurisdictional claims in published maps and institutional affiliations.

Copyright: (c) 2021 by the authors. Licensee MDPI, Basel, Switzerland. This article is an open access article distributed under the terms and conditions of the Creative Commons Attribution (CC BY) license (https:// creativecommons.org/licenses/by/ $4.0 /)$.
Abstract: Staphylococcus aureus is one of the major causes of bloodstream infections. The aim of our study was to characterize methicillin-resistant Staphylococcus aureus (MRSA) isolates from blood of patients hospitalized in the Czech Republic between 2016 and 2018. All MRSA strains were tested for antibiotic susceptibility, analyzed by spa typing and clustered using a Based Upon Repeat Pattern (BURP) algorithm. The representative isolates of the four most common spa types and representative isolates of all spa clonal complexes were further typed by multilocus sequence typing (MLST) and staphylococcal cassette chromosome mec (SCCmec) typing. The majority of MRSA strains were resistant to ciprofloxacin (94\%), erythromycin (95.5\%) and clindamycin (95.6\%). Among the 618 strains analyzed, 52 different spa types were detected. BURP analysis divided them into six different clusters. The most common spa types were $\mathrm{t} 003, \mathrm{t} 586, \mathrm{t} 014$ and $\mathrm{t} 002$, all belonging to the CC5 (clonal complex). CC5 was the most abundant MLST CC of our study, comprising of $91.7 \%(n=565)$ of spa-typeable isolates. Other CCs present in our study were CC398, CC22, CC8, CC45 and CC97. To our knowledge, this is the biggest nationwide study aimed at typing MRSA blood isolates from the Czech Republic.

Keywords: Staphylococcus aureus; MRSA; spa typing; MLST; SCCmec typing; clonal analysis; epidemiology

\section{Introduction}

Staphylococcus aureus is an important opportunistic pathogen both in communities and in hospitals. It can cause broad spectrum of diseases, e.g., skin, soft tissue infections, heart, pleuropulmonary and osteoarticular infections [1]. It is considered to be one of the major causes of bloodstream infections (BSI) in Europe [2]. It was reported that a patient with bacteremia caused by methicillin-resistant Staphylococcus aureus (MRSA) is at a higher risk of all-cause mortality than a patient infected by methicillin-susceptible Staphylococcus aureus (MSSA) [3]. According to the European Antimicrobial Resistance Surveillance Network (EARS-Net) data, the proportion of MRSA isolates from blood from 2005 (until 2018) in the Czech Republic was around 14\% (in the preceding years it was lower, from $4.3 \%$ to $8.5 \%$ ) [4]. It is important to type MRSA isolates to get an insight into epidemiology, limit its possible spread or imply the infection control measures. Studies conducted over time engaged with typing Czech MRSA strains using different molecular 
methods such as multilocus sequence typing (MLST), staphylococcal cassette chromosome mec (SCCmec) typing, pulsed-field gel electrophoresis (PFGE) and ribotyping revealed clonal replacements. In 1996-1997 the most common MRSA clone was Brazilian clone (ST239, SCCmecIIIA, PFGE type B, ribotype H1) and Iberian clone (ST247, SCCmecIA, PFGE type A, ribotype H2) [5]. Around the year 2000, Brazilian clone was replaced by a unique "Czech clone". They differed only in PFGE type and ribotype (F and H6 for the Czech clone, respectively) [6]. After 2001, epidemic clone EMRSA-15 (ST22, SCCmecIV) was detected increasingly [7]. Another clonal replacement was detected using staphylococcal protein A typing method (spa typing). Grundmann et al. [8] in his multicentric European study showed that the majority of Czech MRSA blood isolates from 2006-2007 period were typed as $\mathrm{t} 003$ (t003/ST225/SCCmecII). The retrospective typing of staphylococcal protein A gene of Czech MRSA blood isolates revealed that the clonal replacement took place in 2004, when the most common spa type 0030 isolates were replaced by t003 isolates [9]. It was accompanied by the shift of antibiotic susceptibility of rifampicin and gentamicin [9]. Type t003 was the second most common MRSA spa type from bloodstream infections in 2011 in Europe [3]. As the previous studies have shown, the dominance of MRSA clones undergoes dynamic changes. The aim of our study was to type Czech MRSA blood isolates phenotypically (antibiotic susceptibility), genotypically (spa typing, MLST, SCCmec typing) and to infer their clonal relatedness by clustering them using Based Upon Repeat Pattern (BURP) algorithm.

\section{Results}

\subsection{Antimicrobial Susceptibility of MRSA Strains}

In total, in the 2016-2018 period, 618 single-patient MRSA blood isolates from the participating Czech EARS-Net laboratories were sent and analyzed in the National Reference Laboratory for Antibiotics (NRL for ATB), National Institute of Public Health (Prague, the Czech Republic). Resistance to methicillin (screened by cefoxitine disc [30 $\mu \mathrm{g}]$ ) was confirmed by PCR for mec genes. All MRSA strains possessed an mecA gene (and were $m e c C$ negative). The majority of strains were resistant to erythromycin $(n=590 ; 95.5 \%)$, clindamycin $(\mathrm{n}=591$ (including 76 strains with inducible resistance); $95.6 \%)$, and ciprofloxacin $(\mathrm{n}=581 ; 94.0 \%)$. Only 77 strains $(12.5 \%)$ were resistant to gentamicin, $53(8.6 \%)$ to chloramphenicol and $48(7.8 \%)$ to tetracycline. The resistance to other antibiotics was rare: 15 strains $(2.4 \%)$ were resistant to fusidic acid, $13(2.1 \%)$ to rifampicin, $9(1.5 \%)$ to trimetho$\mathrm{prim} / \mathrm{sulfamethoxazole}$ and $6(1.0 \%)$ to ceftaroline. All the confirmed MRSA isolates were susceptible to tigecycline, vancomycin and linezolid. The frequency of antibiotic resistance $(\%)$ over the study period is shown in Figure 1 . The majority of strains $(\mathrm{n}=600 ; 97.1 \%)$ were multidrug-resistant (MDR; i.e., non-susceptibility to at least one agent in three or more antimicrobial categories [10]). The most common MDR antibiotic resistance profile (resistance to cefoxitine, erythromycin, clindamycin and ciprofloxacin) was present in 429 $(69.4 \%)$ strains. The more detailed characteristics of all the isolates from our study are shown in the Supplementary Table S1. 


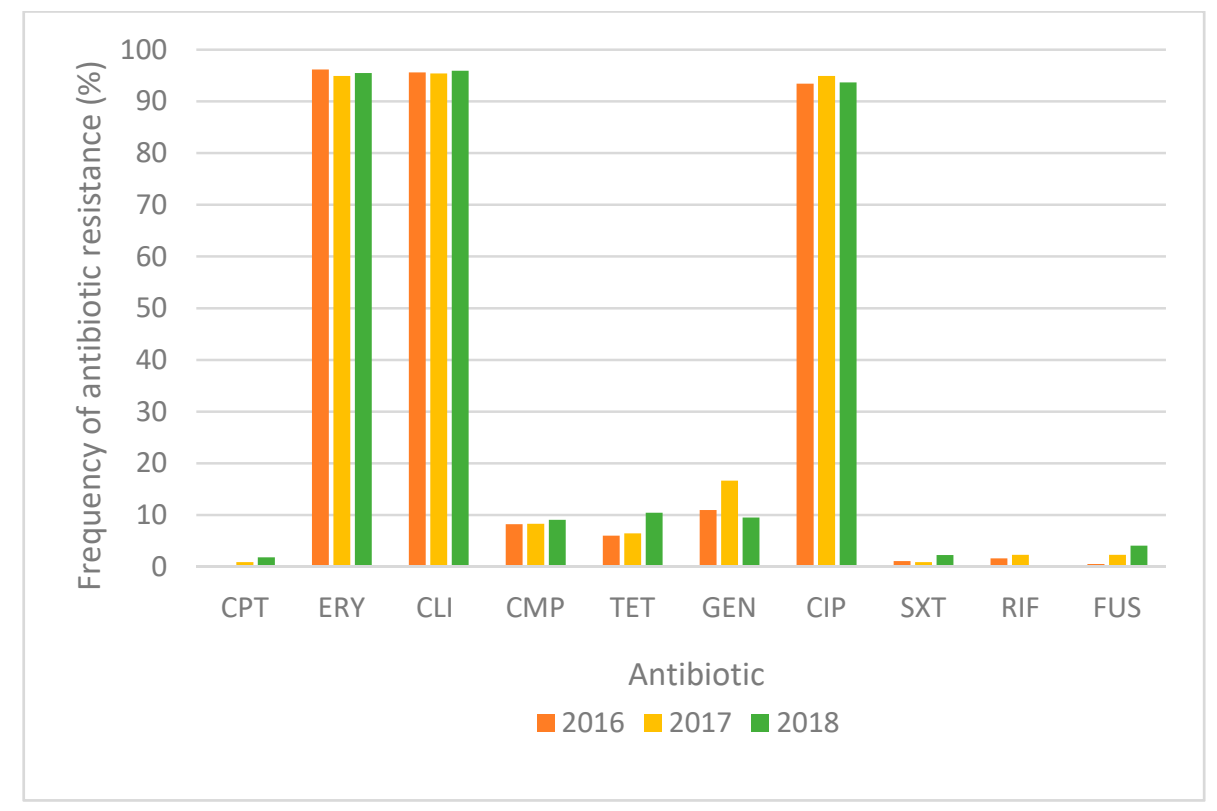

Figure 1. Frequency of antibiotic resistance (\%) of the 618 single-patient MRSA blood isolates over the study period (2016-2018). CPT: ceftaroline, ERY: erythromycin, CLI: clindamycin, CMP: chloramphenicol, TET: tetracycline, GEN: gentamicin, CIP: ciprofloxacin, SXT: trimethoprim/sulfamethoxazole, RIF: rifampicin, FUS: fusidic acid. All the isolates were resistant to cefoxitine and susceptible to tigecycline, vancomycin and linezolid.

\section{2. spa Typing, Cluster Analysis and Antibiotic Susceptibility within spa CCs}

Altogether, 52 different spa types were detected in this study (Figure 2). Four spa types were dominant: $\mathrm{t} 003(\mathrm{n}=239 ; 38.8 \%), \mathrm{t} 586(\mathrm{n}=129 ; 20.9 \%), \mathrm{t} 014(\mathrm{n}=121 ; 19.6 \%)$ and $\mathrm{t} 002$ $(\mathrm{n}=27 ; 4.4 \%)$. They were followed by $\mathrm{t} 034(\mathrm{n}=8 ; 1.3 \%), \mathrm{t} 045(\mathrm{n}=8 ; 1.3 \%)$ and $\mathrm{t} 127(\mathrm{n}=7$; $1.1 \%)$. Several spa types $(\mathrm{n}=28 ; 53.8 \%)$ were detected only once. Two strains out of 618 $(0.3 \%)$ were not typeable by spa typing.

The proportion of $\mathrm{t} 003$ and $\mathrm{t} 002$ did not differ much over the studied period $(34.7-41.6 \%$ and $3.3-5.1 \%$, respectively). The proportion of $\mathrm{t} 586$ isolates increased from $11.6 \%$ in 2016 to around $25 \%$ in the subsequent years. The proportion of $\mathrm{t} 014$ isolates decreased to $14.2 \%$ in 2018 (from more than $20 \%$ in the preceding years).

The majority of the spa-typeable isolates $(n=465 ; 75.5 \%)$ were grouped into 6 different clusters (4 spa CCs) (Figure 2). Cluster 5 and 6 did not have any founder and were not assigned into any spa CC ( $n=5$ strains; $0.8 \%)$. Several strains $(n=17 ; 2.8 \%)$ belonging to 6 different spa types were singletons. BURP algorithm excluded 134 (21.8\%) strains from the analysis because of an inadequate number of repeats (Figure 2).

spa CC003 (cluster number 1) comprised of the greatest number of strains and the three most common spa types (t003, t002 and t014) (Figure 2). The majority of these strains were resistant to erythromycin, clindamycin and ciprofloxacin (Table 1). The second cluster, spa CC011, was the only cluster with a high proportion of tetracycline resistance $(\mathrm{n}=13$; $92.9 \%$ ). The majority of isolates (>50\%) within the two remaining spa CCs (2436 and 024) were resistant to erythromycin and ciprofloxacin. Five isolates (71.4\%) from spa CC2436 were also clindamycin resistant; the resistance was inducible in 4 out of 5 aforementioned isolates. Gentamicin resistance $(66.7 \%)$ was higher among isolates belonging to the cluster number 6 (no founder); however, this cluster did not consist of the representative number of isolates. The percentage of MDR strains and the number of resistances to different antibiotics for each spa CC is shown in Table 1. 

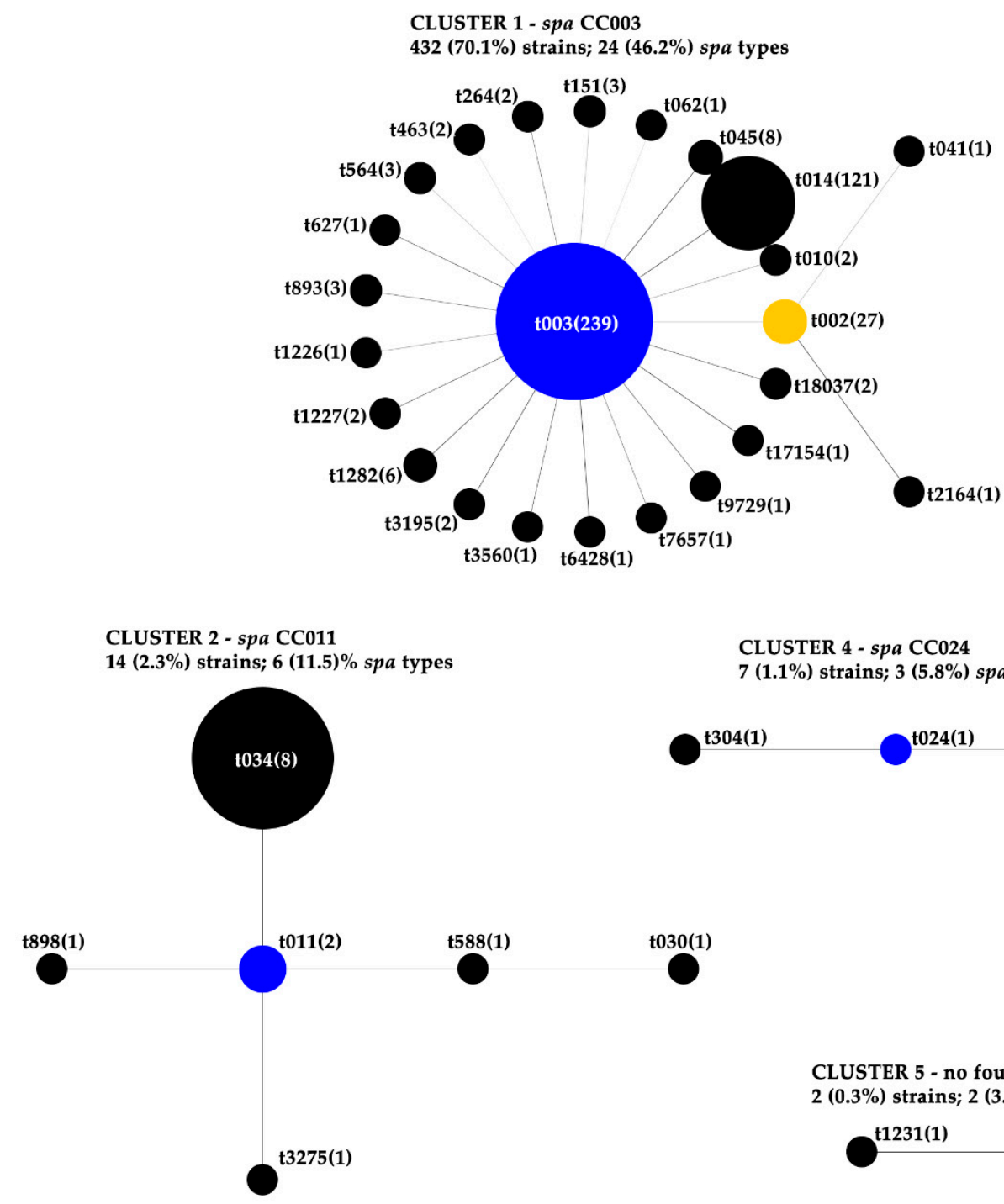

CLUSTER 4 - spa CC024

$7(1.1 \%)$ strains; $3(5.8 \%)$ spa types

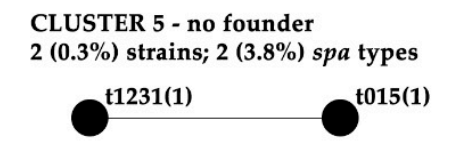

CLUSTER 6 - no founder $3(0.5 \%)$ strains; $2(3.8 \%)$ spa types

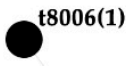

CLUSTER 3 - spa CC2436

$7(1.1 \%)$ strains; $5(9.6 \%)$ spa types
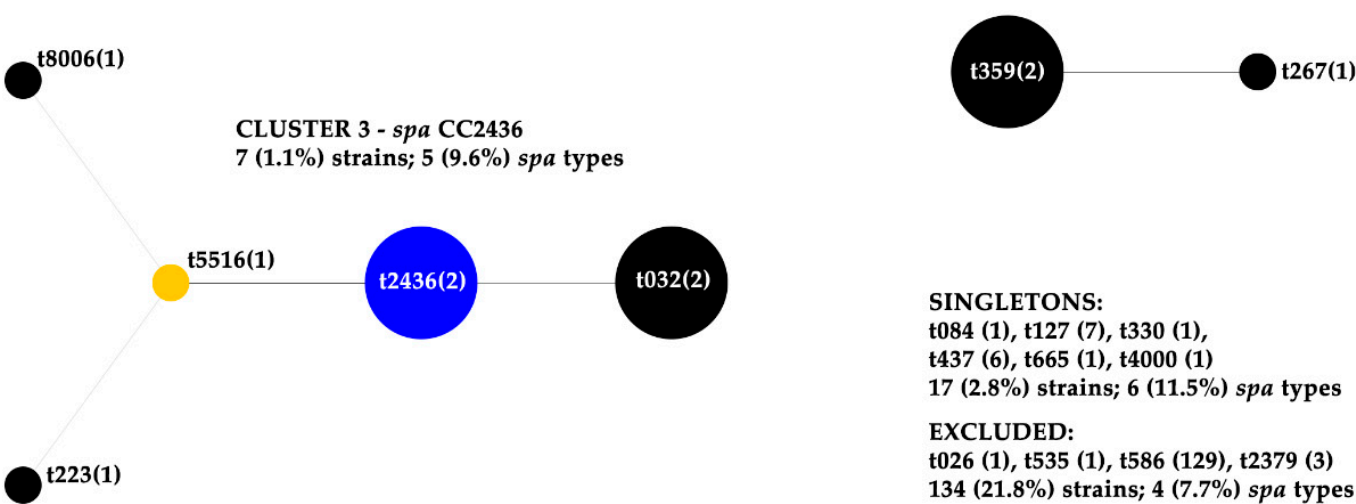

\author{
SINGLETONS: \\ t084 (1), t127 (7), t330 (1), \\ t437 (6), t665 (1), t4000 (1) \\ $17(2.8 \%)$ strains; 6 (11.5\%) spa types \\ EXCLUDED: \\ t026 (1), t535 (1), t586 (129), t2379 (3) \\ 134 (21.8\%) strains; 4 (7.7\%) spa types
}

Figure 2. Based Upon Repeat Pattern (BURP) clustering of the spa-typed isolates. Isolates were clustered by Ridom Staph Type software using the following parameters: spa types were clustered if the cost was less or equal 6 and spa types that were shorter than 4 repeats were excluded from the analysis. The number in brackets represents number of isolates. The majority of the spa typeable isolates $(75.5 \%)$ were grouped into 6 different clusters; $21.8 \%$ of the isolates were excluded from analysis and $2.8 \%$ of isolates were evaluated as singletons. 
Table 1. Antibiotic resistance profiles of different spa clusters (clonal complexes) and multidrug-resistance within spa clusters.

\begin{tabular}{|c|c|c|c|c|c|c|c|c|c|c|c|c|c|c|}
\hline \multirow{2}{*}{ Cluster } & \multirow{2}{*}{ spa CC } & \multirow{2}{*}{$\begin{array}{l}\text { No. }(\%) \text { of } \\
\text { Strains }{ }^{1}\end{array}$} & \multicolumn{10}{|c|}{ No. $(\%)$ of Strains Resistant to Antibiotics ${ }^{2}$} & \multirow{2}{*}{$\begin{array}{c}\text { No. }(\%) \text { of MDR } \\
\text { Strains }\end{array}$} & \multirow{2}{*}{$\begin{array}{l}\text { No. of Resistant ATB } \\
\text { (Mean Value) }^{3}\end{array}$} \\
\hline & & & CPT & ERY & CLI & CMP & TET & GEN & CIP & SXT & RIF & FUS & & \\
\hline 1 & 003 & $\begin{array}{c}432 \\
(70.1)\end{array}$ & $\begin{array}{c}5 \\
(1.2)\end{array}$ & $\begin{array}{c}426 \\
(98.6)\end{array}$ & $\begin{array}{c}426 \\
(98.6)\end{array}$ & $\begin{array}{c}36 \\
(8.3)\end{array}$ & $\begin{array}{c}10 \\
(2.3)\end{array}$ & $\begin{array}{c}35 \\
(8.1)\end{array}$ & $\begin{array}{c}428 \\
(99.1)\end{array}$ & $\begin{array}{c}6 \\
(1.4)\end{array}$ & $\begin{array}{c}8 \\
(1.9)\end{array}$ & $\begin{array}{c}10 \\
(2.3)\end{array}$ & $\begin{array}{c}427 \\
(98.8)\end{array}$ & 4.2 \\
\hline 2 & 011 & $\begin{array}{c}14 \\
(2.3)\end{array}$ & 0 & $\begin{array}{c}7 \\
(50.0)\end{array}$ & $\begin{array}{c}12 \\
(85.7)\end{array}$ & 0 & $\begin{array}{c}13 \\
(92.9)\end{array}$ & $\begin{array}{c}2 \\
(14.3)\end{array}$ & $\begin{array}{c}6 \\
(42.9)\end{array}$ & $\begin{array}{c}1 \\
(7.1)\end{array}$ & $\begin{array}{c}1 \\
(7.1)\end{array}$ & 0 & $\begin{array}{c}14 \\
(100)\end{array}$ & 4.0 \\
\hline 3 & 2436 & $\begin{array}{c}7 \\
(1.1)\end{array}$ & 0 & $\begin{array}{c}5 \\
(71.4)\end{array}$ & $\begin{array}{c}5 \\
(71.4)\end{array}$ & 0 & 0 & 0 & $\begin{array}{c}6 \\
(85.7)\end{array}$ & 0 & 0 & 0 & $\begin{array}{c}5 \\
(71.4)\end{array}$ & 3.3 \\
\hline 4 & 024 & $\begin{array}{c}7 \\
(1.1)\end{array}$ & 0 & $\begin{array}{c}5 \\
(71.4)\end{array}$ & $\begin{array}{c}2 \\
(28.6)\end{array}$ & 0 & 0 & $\begin{array}{c}2 \\
(28.6)\end{array}$ & $\begin{array}{c}4 \\
(57.1)\end{array}$ & 0 & 0 & $\begin{array}{c}1 \\
(14.3)\end{array}$ & $\begin{array}{c}4 \\
(57.1)\end{array}$ & 3 \\
\hline 5 & $\begin{array}{c}\text { no } \\
\text { founder }\end{array}$ & $\begin{array}{c}2 \\
(0.3) \\
\end{array}$ & 0 & 0 & 0 & 0 & 0 & 0 & 0 & 0 & 0 & 0 & 0 & 1 \\
\hline 6 & $\begin{array}{c}\text { no } \\
\text { founder }\end{array}$ & $\begin{array}{c}3 \\
(0.5)\end{array}$ & 0 & 0 & 0 & 0 & 0 & $\begin{array}{c}2 \\
(66.7)\end{array}$ & 0 & 0 & 0 & $\begin{array}{c}1 \\
(33.3)\end{array}$ & $\begin{array}{c}1 \\
(33.3)\end{array}$ & 2 \\
\hline
\end{tabular}

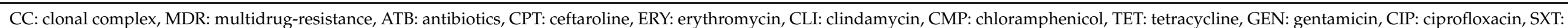

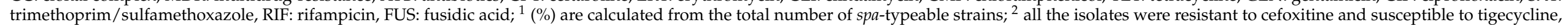

vancomycin and linezolid; ${ }^{3}$ number of resistances to the different antibiotics including cefoxitine. 


\section{3. spa Types and Resistance to Tetracycline}

The high proportion of tetracycline resistance within spa CC011 prompted us to investigate its prevalence among the different spa types further. A high prevalence was detected in strains belonging to spa type $\mathrm{t} 011(\mathrm{n}=2 ; 100 \%), \mathrm{t} 034(\mathrm{n}=7 ; 87.5 \%), \mathrm{t} 127(\mathrm{n}=6$; $85.7 \%)$ and $\mathrm{t} 437(\mathrm{n}=4 ; 66.7 \%)$. These spa types either belonged to spa CC011 (t011 and $\mathrm{t} 034$ ) or were classified as singletons ( $\mathrm{t} 127, \mathrm{t} 437)$. The four most common spa types, $\mathrm{t} 586$, $\mathrm{t} 003, \mathrm{t} 014$ and $\mathrm{t} 002$, had a low proportion of resistance to tetracycline: $\mathrm{n}=13(10.1 \%), \mathrm{n}=6$ $(2.5 \%), \mathrm{n}=3(2.5 \%)$ and $\mathrm{n}=0(0 \%)$, respectively.

\subsection{MLST, SCCmec Typing and MLST CCs in Relation to the Different spa CCs (BURP Clustering)}

Representative isolates differing in antibiotic susceptibility profile of each spa CC (or cluster), together with singletons and strains excluded from BURP analysis, were further analyzed by MLST and SCCmec typing. Altogether, 40 isolates were typed: nine isolates belonging to spa cluster 1 (spa CC003), five isolates from cluster 2 (spa CC011), four isolates from cluster 3 (spa CC2436), three isolates from cluster 4 (spa CC024), two isolates belonging to cluster 5, three isolates from cluster 6, six isolates classified as singletons and eight strains excluded from BURP analysis because of inadequate number of repeats (Table 2).

In total, thirteen different MLST sequence types (STs) were typed among the 40 aforementioned isolates: ST1 $(\mathrm{n}=1)$, ST5 $(\mathrm{n}=2)$, ST8 $(\mathrm{n}=3)$, ST22 $(\mathrm{n}=4)$, ST45 $(\mathrm{n}=4)$, ST59 $(n=1)$, ST72 ( $n=1)$, ST97 $(n=3)$, ST225 ( $n=13)$, ST398 $(n=5)$, ST1472 $(n=1)$, ST1535 $(\mathrm{n}=1)$ and ST5688 $(\mathrm{n}=1$, new ST). They belonged to MLST CC1 (ST1), CC5 (ST225, ST5, ST5688), CC8 (ST8, ST72), CC15 (ST1535), CC22 (ST22), CC30 (ST1472), CC45 (ST45), CC59 (ST59), CC97 (ST97) and CC398 (ST398).

Strains were clustered in the same way either by BURP analysis or by Bionumerics software (MLST CC) with the exception of the two spa types. $t 4000$ and $t 330$ (classified as singletons by BURP analysis) belonged to MLST CC 8 and CC45, respectively. For the more detailed relationship between different spa types and MLST CCs, see Table 2.

Four different SCCmec types were detected in our study. Isolates belonging to MLST CC5 were mainly typed as SCCmecII (15/16 isolates). Isolates belonging to other MLST CCs possessed either $\mathrm{SCCmecIV,} \mathrm{V}$ or $\mathrm{V}_{\mathrm{T}}$ type (Table 2).

Table 2. Results of the more detailed genotyping of the representative isolates differing in antibiotic susceptibility profiles belonging to the different spa clusters, singletons or strains excluded from BURP analysis.

\begin{tabular}{|c|c|c|c|c|c|c|c|}
\hline Strain & spa Type & spa Cluster & spa CC & MLST ST & MLST CC & SCCmec Type & Resistance to Antibiotics ${ }^{1}$ \\
\hline B0040949 & t003 & 1 & 003 & 225 & CC5 & II & CIP, GEN, ERY, CLI \\
\hline B0041781 & t003 & 1 & 003 & 225 & CC5 & II & CMP, CIP, RIF, ERY, CLI \\
\hline B0047063 & t003 & 1 & 003 & 225 & CC5 & II & CIP, ERY, CLI \\
\hline B0034821 & $\mathrm{t} 586$ & excluded & excluded & 225 & CC5 & II & CMP, CIP, GEN, ERY, CLI, \\
\hline B0038966 & $\mathrm{t} 586$ & excluded & excluded & 225 & CC5 & II & CIP, ERY, CLI \\
\hline В0043165 & $\mathrm{t} 586$ & excluded & excluded & 225 & CC5 & II & CIP, GEN, ERY, CLI, TET \\
\hline B0037533 & t014 & 1 & 003 & 225 & CC5 & II & CIP, GEN \\
\hline В0040744 & t014 & 1 & 003 & 225 & CC5 & II & CIP, GEN, ERY, CLI \\
\hline B0047366 & t014 & 1 & 003 & 225 & CC5 & II & CIP, ERY, CLI \\
\hline В0037993 & t002 & 1 & 003 & 5 & CC5 & II & CMP, CIP, GEN, ERY, CLI \\
\hline B0040837 & t002 & 1 & 003 & 5688 & CC5 & IV & - \\
\hline B0042384 & t002 & 1 & 003 & 5 & CC5 & II & CIP, ERY, CLI \\
\hline В0033841 & $\mathrm{t} 535$ & excluded & excluded & 225 & CC5 & II & CIP, ERY, CLI \\
\hline B0039941 & t2379 & excluded & excluded & 225 & CC5 & II & CIP, ERY, CLI \\
\hline В0040619 & t2379 & excluded & excluded & 225 & CC5 & II & CIP, ERY, CLI \\
\hline B0047250 & t2379 & excluded & excluded & 225 & CC5 & II & CIP, ERY, CLI \\
\hline B0038416 & t011 & 2 & 011 & 398 & CC398 & V & CIP, TET \\
\hline B0046007 & t011 & 2 & 011 & 398 & CC398 & IV & CIP, GEN, SXT, TET \\
\hline В0037087 & t034 & 2 & 011 & 398 & CC398 & $\mathrm{V}$ & CLI, TET \\
\hline B0043212 & t034 & 2 & 011 & 398 & CС398 & V & CIP, CLI, TET \\
\hline B0044843 & t034 & 2 & 011 & 398 & CC398 & V & ERY, CLI, TET \\
\hline
\end{tabular}


Table 2. Cont.

\begin{tabular}{|c|c|c|c|c|c|c|c|}
\hline Strain & spa Type & spa Cluster & spa CC & MLST ST & MLST CC & SCCmec Type & Resistance to Antibiotics ${ }^{1}$ \\
\hline B0034866 & $\mathrm{t} 032$ & 3 & 2436 & 22 & CC22 & IV & CIP \\
\hline B0039472 & $\mathrm{t} 032$ & 3 & 2436 & 22 & CC22 & IV & CIP, ERY, CLI \\
\hline B0036602 & $\mathrm{t} 2436$ & 3 & 2436 & 22 & $\mathrm{CC} 22$ & IV & CIP, ERY, CLI \\
\hline B0040230 & $\mathrm{t} 2436$ & 3 & 2436 & 22 & $\mathrm{CC} 22$ & IV & CIP, ERY, CLI \\
\hline B0034699 & t008 & 4 & 024 & 8 & $\mathrm{CC} 8$ & nt & ERY \\
\hline B0043674 & t008 & 4 & 024 & 8 & $\mathrm{CC} 8$ & IV & CIP, ERY \\
\hline B0043848 & t008 & 4 & 024 & 8 & CC8 & IV & CIP, ERY, CLI \\
\hline B0045550 & $\mathrm{t} 4000$ & singleton & singleton & 72 & $\mathrm{CC} 8$ & nt & GEN, FUS \\
\hline B0043746 & t015 & 5 & no founder & 45 & CC45 & IV & - \\
\hline B0044462 & $\mathrm{t} 1231$ & 5 & no founder & 45 & CC45 & IV & - \\
\hline B0032812 & $\mathrm{t} 026$ & excluded & excluded & 45 & CC45 & IV & - \\
\hline B0033429 & $\mathrm{t} 330$ & singleton & singleton & 45 & CC45 & IV & ERY, CLI \\
\hline B0040776 & $\mathrm{t} 267$ & 6 & no founder & 97 & CC97 & $\mathrm{V}$ & GEN \\
\hline B0037227 & t359 & 6 & no founder & 97 & CC97 & V & GEN, FUS \\
\hline B0048151 & t359 & 6 & no founder & 97 & CC97 & IV & - \\
\hline B0048051 & t084 & singleton & singleton & 1535 & CC15 & $\mathrm{V}$ & GEN, FUS, TET \\
\hline B0042118 & $\mathrm{t} 127$ & singleton & singleton & 1 & $\mathrm{CC} 1$ & IV & ERY, CLI, TET \\
\hline B0040853 & $\mathrm{t} 437$ & singleton & singleton & 59 & CC59 & $\mathrm{V}_{\mathrm{T}}$ & CMP, ERY, CLI, TET \\
\hline B0033532 & t665 & singleton & singleton & 1472 & CC30 & IV & CIP, ERY, TET \\
\hline
\end{tabular}

CC: clonal complex, ST: sequence type, ERY: erythromycin, CLI: clindamycin, CMP: chloramphenicol, TET: tetracycline, GEN: gentamicin, CIP: ciprofloxacin, SXT: trimethoprim/sulfamethoxazole, RIF: rifampicin, FUS: fusidic acid; ${ }^{1}$ cefoxitine is not listed in the antibiotic resistance profiles, since all the isolates were resistant.

\subsection{Distribution of the Major spa Types and MLST CCs among the Czech Regions}

Figure 3 and Table 3 show the distribution of the four major spa types and MLST CCs among the Czech regions. t003 strains were sent to NRL for ATB from all the Czech regions ( $\mathrm{n}=13$; except the Moravian-Silesian, from which we did not obtain any MRSA strains). t003 was ubiquitous. It was dominant in the eastern part of the country: in the Olomouc region it was the only spa type detected and in Zlin region it represented more than $90 \%$ of the isolates. t586 strains ( $\geq 25 \%$ of the strains) were mainly isolated from the northwestern, southwestern and middle western part of the country. t014 strains were not detected in three regions (eastern/southeastern part of the country) and t002 strains in five regions.

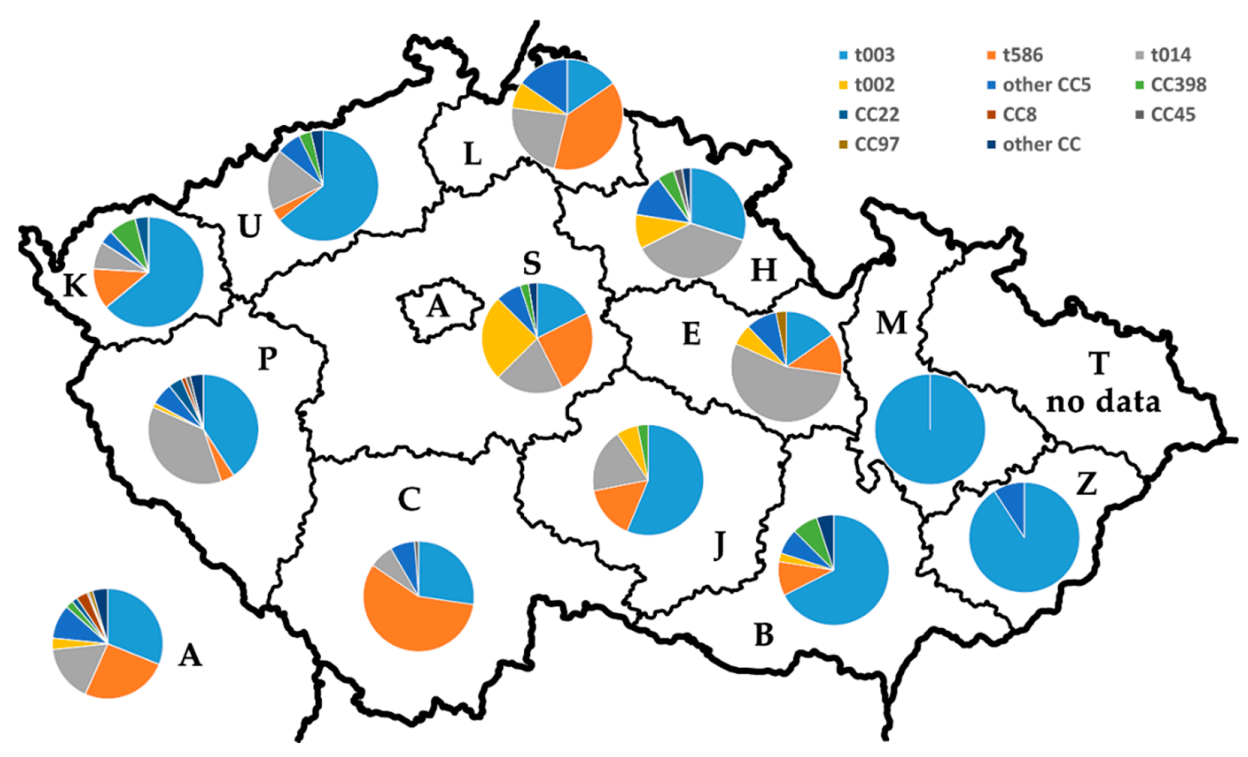

Figure 3. The distribution of the major spa types and MLST CCs among the Czech regions. A: Prague Region; S: Central Bohemian Region; C: South Bohemian Region; P: Pilsen Region; K: Karlovy Vary Region; U: Usti nad Labem Region; L: Liberec Region; H: Hradec Kralove Region; E: Pardubice Region; J: Vysocina Region; B: South Moravian Region; M: Olomouc Region; T: Moravian-Silesian Region; Z: Zlin Region. 
Table 3. The total number of participating laboratories, isolates and distribution of the major spa types and strains belonging to the different MLST CCs among the Czech regions.

\begin{tabular}{|c|c|c|c|c|c|c|c|c|c|c|c|c|c|c|}
\hline \multirow{3}{*}{ Region } & \multirow{3}{*}{$\begin{array}{l}\text { No. of Particip. } \\
\text { Laboratories }\end{array}$} & \multirow{3}{*}{$\begin{array}{l}\text { No. of } \\
\text { Isolates }\end{array}$} & \multirow{3}{*}{$\begin{array}{l}\text { No. of spa } \\
\text { Types }\end{array}$} & \multicolumn{11}{|c|}{ No. (\%) of Isolates } \\
\hline & & & & \multicolumn{5}{|c|}{ CC5 } & \multirow{2}{*}{ CC398 } & \multirow{2}{*}{$\mathrm{CC} 22$} & \multirow{2}{*}{$\mathrm{CC} 8$} & \multirow{2}{*}{ CC45 } & \multirow{2}{*}{ CC97 } & \multirow{2}{*}{$\begin{array}{l}\text { Other } \\
\text { CCs }\end{array}$} \\
\hline & & & & t003 & t586 & to14 & t002 & Other & & & & & & \\
\hline $\begin{array}{l}\text { Central } \\
\text { Bohemian }\end{array}$ & 4 & 40 & 8 & $\begin{array}{c}7 \\
(17.5)\end{array}$ & $\begin{array}{l}10 \\
(25)\end{array}$ & $\begin{array}{c}8 \\
(20)\end{array}$ & $\begin{array}{c}10 \\
(25)\end{array}$ & $\begin{array}{c}3 \\
(7.5)\end{array}$ & $\begin{array}{c}1 \\
(2.5)\end{array}$ & 0 & 0 & 0 & 0 & $\begin{array}{c}1 \\
(2.5)\end{array}$ \\
\hline South Bohemian & 4 & 84 & 9 & $\begin{array}{c}23 \\
(27.4)\end{array}$ & $\begin{array}{c}48 \\
(57.1)\end{array}$ & $\begin{array}{c}6 \\
(7.1)\end{array}$ & 0 & $\begin{array}{c}6 \\
(7.1)\end{array}$ & 0 & 0 & 0 & $\begin{array}{c}1 \\
(1.2)\end{array}$ & 0 & 0 \\
\hline Pilsen & 2 & 76 & 15 & $\begin{array}{c}31 \\
(40.8)\end{array}$ & $\begin{array}{c}3 \\
(3.9)\end{array}$ & $\begin{array}{c}28 \\
(36.8)\end{array}$ & $\begin{array}{c}1 \\
(1.3)\end{array}$ & $\begin{array}{c}5 \\
(6.6)\end{array}$ & 0 & $\begin{array}{c}3 \\
(3.9)\end{array}$ & $\begin{array}{c}1 \\
(1.3)\end{array}$ & $\begin{array}{c}1 \\
(1.3)\end{array}$ & 0 & $\begin{array}{c}3 \\
(3.9)\end{array}$ \\
\hline Karlovy Vary & 1 & 25 & 7 & $\begin{array}{l}16 \\
(64)\end{array}$ & $\begin{array}{c}3 \\
(12)\end{array}$ & $\begin{array}{c}2 \\
(8)\end{array}$ & 0 & $\begin{array}{c}1 \\
(4)\end{array}$ & $\begin{array}{c}2 \\
(8)\end{array}$ & $\begin{array}{c}1 \\
(4)\end{array}$ & 0 & 0 & 0 & 0 \\
\hline Usti nad Labem & 2 & 28 & 7 & $\begin{array}{c}18 \\
(64.2)\end{array}$ & $\begin{array}{c}1 \\
(3.6)\end{array}$ & $\begin{array}{c}5 \\
(17.8)\end{array}$ & 0 & $\begin{array}{c}2 \\
(7.1)\end{array}$ & $\begin{array}{c}1 \\
(3.6)\end{array}$ & 0 & 0 & 0 & 0 & $\begin{array}{c}1 \\
(3.6)\end{array}$ \\
\hline Liberec & 1 & 13 & 5 & $\begin{array}{c}2 \\
(15.4)\end{array}$ & $\begin{array}{c}5 \\
(38.5)\end{array}$ & $\begin{array}{c}3 \\
(23)\end{array}$ & $\begin{array}{c}1 \\
(7.7)\end{array}$ & $\begin{array}{c}2 \\
(15.4)\end{array}$ & 0 & 0 & 0 & 0 & 0 & 0 \\
\hline Hradec Kralove & 3 & 40 & 9 & $\begin{array}{c}12 \\
(30)\end{array}$ & 0 & $\begin{array}{c}15 \\
(37.5)\end{array}$ & $\begin{array}{c}4 \\
(10)\end{array}$ & $\begin{array}{c}5 \\
(12.5)\end{array}$ & $\begin{array}{c}2 \\
(5)\end{array}$ & 0 & 0 & $\begin{array}{c}1 \\
(2.5)\end{array}$ & 0 & $\begin{array}{c}1 \\
(2.5)\end{array}$ \\
\hline Pardubice & 3 & 33 & 8 & $\begin{array}{c}5 \\
(15.2)\end{array}$ & $\begin{array}{c}4 \\
(12.1)\end{array}$ & $\begin{array}{c}18 \\
(54.5)\end{array}$ & $\begin{array}{c}2 \\
(6.06)\end{array}$ & $\begin{array}{c}3 \\
(9.1)\end{array}$ & 0 & 0 & 0 & 0 & $\begin{array}{c}1 \\
(3.0)\end{array}$ & 0 \\
\hline Vysocina & 4 & 32 & 5 & $\begin{array}{c}18 \\
(56.3)\end{array}$ & $\begin{array}{c}5 \\
(15.6)\end{array}$ & $\begin{array}{c}6 \\
(18.8)\end{array}$ & $\begin{array}{c}2 \\
(6.2)\end{array}$ & 0 & $\begin{array}{c}1 \\
(3.1)\end{array}$ & 0 & 0 & 0 & 0 & 0 \\
\hline South Moravian & 2 & 40 & 10 & $\begin{array}{c}27 \\
(67.5)\end{array}$ & $\begin{array}{c}4 \\
(10.0)\end{array}$ & 0 & $\begin{array}{c}1 \\
(2.5)\end{array}$ & $\begin{array}{c}3 \\
(7.5)\end{array}$ & $\begin{array}{c}3 \\
(7.5)\end{array}$ & 0 & 0 & 0 & 0 & $\begin{array}{c}2 \\
(5.0)\end{array}$ \\
\hline Olomouc & 1 & 14 & 1 & $\begin{array}{c}14 \\
(100.0)\end{array}$ & 0 & 0 & 0 & 0 & 0 & 0 & 0 & 0 & 0 & 0 \\
\hline Zlin & 1 & 11 & 2 & $\begin{array}{c}10 \\
(90.9)\end{array}$ & 0 & 0 & 0 & $\begin{array}{c}1 \\
(9.1)\end{array}$ & 0 & 0 & 0 & 0 & 0 & 0 \\
\hline
\end{tabular}




\section{Discussion}

In our study we analyzed genotypically and phenotypically 618 MRSA strains isolated from blood of patients hospitalized in the Czech Republic in period 2016-2018. It represents $75 \%$ of the Czech MRSA isolates submitted to the EARS-Net.

We demonstrate that the majority of MRSA strains in our study are resistant to erythromycin, clindamycin and ciprofloxacin. A recent study from the Czech Republic also confirmed the high frequency of MRSA isolates resistant to antibiotics from the same classes (erythromycin, clindamycin and ofloxacin); however, only $4.5 \%$ of the studied MRSA isolates were derived from bloodstream infections (BSI) [11]. The earlier study concerning the antibiotic resistance of blood isolates from the Czech Republic (collection of MRSA blood isolates from 20 hospitals from the 2000-2002 period) reported resistance to more antibiotics (also gentamicin and rifampicin) [6]. This shift in a resistance phenotype is a result of clonal displacement (from ST239 to ST225 and ST5) [6,9].

We detected 52 different spa types among 616 spa-typeable MRSA strains. The most common spa types included t003, t586, $\mathrm{t} 014$ and $\mathrm{t} 002$, respectively. Type 003 is the most prevalent spa type from blood isolates in the Czech Republic from 2004 [9]. Our result concerning the high abundance of $\mathrm{t} 003, \mathrm{t} 002$ and $\mathrm{t} 014$ is in concordance with the multicentric European study that spa-typed MRSA blood isolates collected in 25 European countries, where $\mathrm{t} 003$ was reported to be the second most common, t002 the fourth and t014 the twentieth most common spa type [3]. High prevalence of t003, t586 and t014 was also detected in a recent Czech study investigating MRSA strains originating from various infections [11]. Neradova et al. detected a high proportion of t003, t002 and t014 from BSI from the Czech university hospital [12]. Types t003 and t014 were also detected to be the dominant spa types in a study investigating MRSA outbreak in the intensive care unit in the Czech tertiary care hospital [13]. Interesting is the high proportion of t586 (20.9\% of the isolates) in our study. According to the Ridom Spa server database [14], this spa type has been reported in many European countries (e.g., Germany, Netherlands, France, Belgium, Croatia, Norway, Spain); however, to our knowledge, there has not been any other country detecting such a high proportion of it. MRSA strains typed as $\mathbf{5} 586$ were isolated from blood of patients hospitalized in the Czech Republic [11]; however, this is the first study detecting it from blood on a nationwide scale.

The spa type distribution varied between the Czech regions. t003 was widespread, it was the most frequently isolated from the eastern part of the country. t586 isolates were frequently isolated from northwestern, southwestern and middle western part of the country (Liberec, Prague, Central Bohemian and South Bohemian regions). Our results corroborate the observation of the recent study conducted by Tkadlec et al. [11] They typed MRSA isolated from various infection sites (or asymptomatic colonization) from 11 Czech hospitals. It is important to note that the dominance of just one spa type (or few) in some regions (our study) does not mean that the other spa types are not present in these parts of the country. The number of participating laboratories from different regions should be taken into consideration. Some laboratories participating in EARS-Net send only data, thus NRL for ATB does not obtain strains for further typing. From some regions we obtain strains from laboratories belonging to small healthcare facilities rather than laboratories from big hospitals. This might underrepresent prevalence of different spa types among the Czech regions in our study.

spa-typeable strains were divided into 6 clusters. Representative strains of each spa CC differing in antibiograms were typed by MLST and SCCmec typing. Our data analysis shows that the clustering results of BURP analysis and results from Bionumerics software (MLST CCs) are comparable. Isolates were clustered in the same way with either of the two aforementioned methods, with the exception of two spa types, which were evaluated as singletons by BURP analysis. Strommenger et al. [15] showed $96.8 \%$ concordance between the two methods (spa typing/BURP and MLST/eBURST).

Altogether, 565 (91.7\%) MRSA strains from our study belonged to CC5. CC5 was reported to be the most abundant MLST CC of staphylococcal isolates from invasive infec- 
tions in Europe, of which 80\% were MRSA [16]. According to the results of more detailed genotyping of the representative strains, we can say that the most common genotype (clone) in our study was ST225/SCCmecII. This correlates with the results of whole-genome sequencing data of MRSA from invasive infections from Aanensen et al. [16] The geographic origin of this clone was Middle Europe, more exactly the Czech Republic and Germany. The European clade of ST225 is the descendant of the American clade. It diverged around 1995 and spread to several European countries (Germany, the Czech Republic, Switzerland and Denmark) [17]. Another clone present in our study, ST5/SCCmecII, was previously characterized as a USA100 clone (New York/Japan Clone) [18-20]. ST5 is an ancestor of ST225 with the variation in one MLST locus [17]. ST5-SCCmecII was reported also in other European countries, e.g., Hungary, Portugal or Austria [21-23]. We might hypothesize that the strain of genotype ST5688/SCCmecIV was derived from the Pediatric clone, which is characterized as ST5/SCCmecIV [24]. The difference between ST5 and ST5688 is only a single nucleotide in the internal fragment of the pta gene.

Our study demonstrates that livestock-associated MRSA (LA-MRSA) were isolated from the human bloodstream infections. The majority of the strains $(92.9 \%)$ in the second cluster (spa CC011-MLST CC398) were resistant to tetracycline, which is a common marker of LA-MRSA [25]. All the t011 (spa CC 011) strains and the majority of the t034 (spa CC $011)$ and t127 strains (singletons) $(87.5 \%$ and $85.7 \%$, respectively) were resistant to the aforementioned antibiotic. The $\mathrm{t} 011$ and 034 isolates were typed as ST398 and possessed SCCmecIV or V element. The presence of the ST398 LA-MRSA strains and related spa types in the Czech Republic was confirmed by several studies. Tegegne et al. [26] reported a wide geographical spread of these strains (isolated from bulk tank milk of cows, sheep and goats) throughout the country. These spa types were detected in more than $90 \%$ of the spa-typed MRSA strains from the Czech livestock animals (pigs, cattle, goats and sheep) as well as from food of animal origin and the environment [27]. A recent study [28] investigated nasal MRSA carriage among veterinary professionals from the Czech Republic. The majority of isolates belonged to ST398 and were clustered into spa CC011. Tkadlec et al. [11] showed that $2.5 \%$ of the MRSA strains isolated from the various infections were of CC398. The results of our study show that LA-MRSA are also able to cause serious infections (bloodstream); however, the prevalence of these strains among MRSA isolated from blood remains low (2.3\%). LA-MRSA ST398 could be the cause of a hospital outbreak, as reported by Wulf et al. [29].

EMRSA-15 (ST22/SCCmecIV) strains appeared in the early nineties and subsequently spread to the various hospitals in the United Kingdom and gradually disseminated to other European countries [30]. After 2001, this epidemic clone was detected in hospitals in the Czech Republic [7]. Our study demonstrates the presence of this clone among the isolates from BSI. Strains typed as ST22/SCCmecIV (spa types t032 and t2436) were grouped in the spa CC2436 (MLST CC22). Faria et al. [31] characterized MRSA isolated from BSI from Portugal, when the majority of them were typed as EMRSA-15. Another study [32] detected the presence of this clone in intensive care units from five different countries (years 2008-2011).

t008, t024, t304 and t4000 strains in our study (spa CC 024 and one singleton) belong to MLST CC8. The presence of t008 and t024 MRSA spa types in BSI in Europe is quite frequent: Grundman et al. [3] showed that t008 is the third most common and t024 is the 15th most common MRSA spa type isolated from blood of patients. Tkadlec et al. [11] detected CC 8 strains ( $\mathrm{t} 008, \mathrm{t} 024$, etc.) to be the second most frequently isolated MLST CC from MRSA infections of various origin from the 11 Czech hospitals. More than $64 \%$ of them were reported to be community associated (CA-MRSA).

Two isolates of t015 and t1231 (spa cluster 5), one t026 isolate (excluded from BURP analysis) and one $\mathrm{t} 330$ isolate (singleton) belong to MLST CC45. In 2006, S. aureus isolated from BSI typed as CC45 was one of the predominant clones circulating in Europe [16]. In our study we demonstrate the presence of the "Berlin IV" clone, which is characterized as ST45/SCCmecIV [33]. All the four aforementioned isolates were of the same genotype. 
This clone was also isolated from a nasal swab of the Czech MRSA carrier in 2008 [34]. This epidemic MRSA was initially isolated in Berlin hospitals in early nineties and subsequently disseminated to other areas of Germany [33,35]. A recent phylogenetic analysis proposes that acquisition of the SCCmecIV element occurred multiple times within the staphylococcal ST45 population [33].

The last spa cluster 6 in our study consisted of two t359 strains and one t267 strain. These isolates were typed as ST97 (MLST CC97). They possessed a SCCmecIV or SCCmecV element. CC97 MRSA strains were isolated from various infections (data from the Czech Republic, $0.9 \%$ of all the strains from the study) and their origin was CA-MRSA [11]. Studies have shown that ST97 MRSA are able to cause hospital outbreak [36,37].

Our study has typed a large collection of samples (75\% of the Czech MRSA blood isolates submitted to EARS-Net in 2016-2018 period). Its limitation lies in a choice of the representative isolates belonging to the different spa CCs (for MLST analysis and SCCmec typing). Not all the spa types within some clonal complexes were further typed (for example, within the spa CC003 we further typed isolates belonging to the three most common spa types and no other rare spa types). This might underrepresent the presented diversity of genotypes.

Our study demonstrates that strains belonging to CC5 (ST225, ST5) are the most prevalent among MRSA isolated from the blood cultures from the Czech Republic. The majority of these strains confer a multidrug-resistant phenotype. Although other clones (e.g., EMRSA-15, Berlin IV) appear sporadically, CC5 clones remain the dominant MRSA bloodstream isolates from 2004.

\section{Materials and Methods}

\subsection{Bacterial Strains}

S. aureus strains isolated from blood of patients hospitalized in Czech hospitals in 2016-2018 were sent to the National Reference Laboratory for Antibiotics (NRL for ATB), National Institute of Public Health (Prague, the Czech Republic), by laboratories participating in EARS-Net, which is the largest publicly funded system for surveillance of antimicrobial resistance in Europe (https:/ / www.ecdc.europa.eu/en/about-us/networks / disease-networks-and-laboratory-networks/ears-net-about, accessed on the 18 December 2020). At least two blood culture (BC) sets were taken and incubated in BC bottles in automatic systems for 5 days. Positive BC bottles were inoculated on blood agar plates and bacterial colonies were subsequently identified by Matrix-Assisted Laser Desorption Ionization-Time of Flight Mass Spectometry (MALDI-TOF) or other commonly used methods [38]. A total number of 1887 S. aureus isolates were reported to EARS-Net in 2016 (45 reporting laboratories), 1944 in 2017 (47 reporting laboratories) and 2244 in 2018 (48 reporting laboratories) (Table 4) [39]. Population sample representativeness, hospital sample representativeness and isolate representativeness was high during the studied period. Blood culture sets/1000 patient days was 18.0 in 2016 and 2017 and 17.0 in 2018 (Table 4) [39]. The staphylococcal isolates data are submitted into EARS-Net annually by the data manager on behalf of the participating laboratories, the majority of the isolates are regularly sent to NRL for ATB for confirmation and further typization. We obtained and analyzed 618 single-patient MRSA strains sent by 37 laboratories over the study period. This number represents $75 \%(n=618 / 824)$ of all the MRSA strains submitted to the EARS-Net. In 2016 it was 69.2\% $(n=182 / 263), 84 \%$ in $2017(n=216 / 257)$ and $72.4 \%$ in 2018 ( $n=220 / 304$ ) (Table 4) [39]. The estimated national population coverage included in the EARS-Net was 85\% in 2016 and 2017. In 2018 it counted for 81\% [39].

Isolates were inoculated on Nutrient Agar (OXOID, the Czech Republic) and cultivated overnight at $35^{\circ} \mathrm{C}$ in aerobic atmosphere. Strain confirmation to the corresponding species was performed using MALDI-TOF (Microflex Bruker; Bremen, Germany) by flexControl software (Bruker Daltonics; Bremen, Germany). 
Table 4. Number of reported isolates and data on the sample representativeness according to EARS-Net and number of MRSA strains sent to NRL for ATB from the participating laboratories in EARS-Net.

\begin{tabular}{|c|c|c|c|c|c|}
\hline & & \multicolumn{3}{|c|}{ Year of the Study } & \multirow{2}{*}{ Reference } \\
\hline & & 2016 & 2017 & 2018 & \\
\hline No. of reported staphylococcal isolates & \multirow[b]{2}{*}{ EARS-Net } & 1887 & 1944 & 2244 & \multirow{2}{*}{ [39] } \\
\hline No. of MRSA (\%) & & $\begin{array}{c}263 \\
(13.9)\end{array}$ & $\begin{array}{c}257 \\
(13.2)\end{array}$ & $304(13.6)$ & \\
\hline $\begin{array}{l}\text { No. of single-patient MRSA strains sent to NRL for ATB from } \\
\text { the laboratories participating in EARS-Net ( } \% \text { are calculated } \\
\text { from the number of MRSA isolates reported in EARS-Net) }\end{array}$ & \multirow[t]{2}{*}{ NRL for ATB } & $\begin{array}{c}182 \\
(69.2)\end{array}$ & $\begin{array}{c}216 \\
(84.0)\end{array}$ & $\begin{array}{c}220 \\
(72.4)\end{array}$ & \multirow[t]{2}{*}{ this study } \\
\hline Number of participating laboratories in our study & & 31 & 37 & 36 & \\
\hline Population sample representativeness & \multirow{5}{*}{ EARS-Net } & high & high & high & \multirow{5}{*}[39]{} \\
\hline Hospital sample representativeness & & high & high & high & \\
\hline Isolate sample representativeness & & high & high & high & \\
\hline Blood culture sets /1000 patient days & & 18.0 & 18.0 & 17.0 & \\
\hline Estimated national population coverage (\%) & & 85 & 85 & 81 & \\
\hline
\end{tabular}

\subsection{Antibiotic Susceptibility Testing and MRSA Detection}

Susceptibility to erythromycin, clindamycin, chloramphenicol, tigecycline, gentamicin, ciprofloxacin, trimethoprim/sulfamethoxazole, rifampicin, fusidic acid, vancomycin and linezolid was tested using broth microdilution method, while susceptibility to ceftaroline and tetracycline by disc diffusion method (according to the EUCAST methodology, breakpoints ver. 9.0-EUCAST 2019 [40]). Susceptibility to ceftaroline was tested using breakpoints for indications other than pneumonia (resistant $<17 \mathrm{~mm}$, susceptible $\geq 20 \mathrm{~mm}$ ). Inducible clindamycin resistance was tested by a broth microdilution method according to the CLSI methodology [41]. Methicillin resistance was screened using cefoxitine disc $(30 \mu \mathrm{g})$. Strains with the zone diameter $<22 \mathrm{~mm}$ were reported as MRSA.

\subsection{Molecular Typing}

\subsection{1. mecA/mecC Detection}

The presence of genes encoding alternative penicillin-binding proteins (methicillin resistance) was confirmed by polymerase chain reaction (PCR) screening for mecA/mecC genes. mecA was detected using P4 (5'-TCC AGA TTA CAA CTT CAC CAG G-3') and P7 (5'-CCA CTT CAT ATC TTG TAA CG-3') primers [42]. PCR conditions were $4 \mathrm{~min}$ at $94^{\circ} \mathrm{C}$, followed by 30 cycles of $45 \mathrm{~s}$ at $94{ }^{\circ} \mathrm{C}, 45 \mathrm{~s}$ at $50{ }^{\circ} \mathrm{C}$ and $1 \mathrm{~min}$ at $72{ }^{\circ} \mathrm{C}$. The final elongation was 2 min at $72{ }^{\circ} \mathrm{C}$ (Bio-Rad, DNA Engine Dyad ${ }^{\circledR}$ Dual-Bay Thermal Cycler; Bio-Rad Laboratories, Hercules, California, USA). mecC gene was detected according to Stegger et al. [43]. All the primers used in our study are listed in the Supplementary Table S2.

\subsection{2. spa Typing and Based Upon Repeat Analysis (BURP)}

In all MRSA isolates, a single locus of the repeat region $X$ of the $S$. aureus protein A gene (spa) was sequenced. DNA amplification and DNA preparation for Sanger sequencing were performed according to the protocol from the official Ridom Spa Server website [44] using primers $1113 \mathrm{f}\left(5^{\prime}\right.$-TAA AGA CGA TCC TTC GGT GAG C-3') and 1514r (5'-CAG CAG TAG TGC CGT TTG CTT-3'). Sequences were evaluated and spa types determined using Ridom StaphType software.

To infer the clonal relatedness based on spa polymorphisms (spa CCs), MRSA strains were clustered by BURP analysis using Ridom StaphType software. Clustering parameters were chosen according to the RidomStaph Type user guide [45]: spa types were clustered if cost was less or equal 6 (value defining cluster dimension, the default value was used) and spa types that were shorter than 4 repeats were excluded (to include the highest number of spa types, the least possible value recommended was used). The strains with inadequate number of repeats were excluded from BURP analysis. 


\subsubsection{Multilocus Sequence Typing (MLST)}

MLST was performed as described by Enright et al. [46] The sequences of the seven approximately $450 \mathrm{bp}$ long internal fragments of the housekeeping genes (carbamate kinase — arcC, shikimate dehydrogenase — aroE, glycerol kinase—glpF, guanylate kinase$g m k$, phosphate acetyltransferase - $p t a$, triosephosphate isomerase- $t p i$ and acetyl coenzyme A acetyltransferase-yqiL) were amplified by PCR and sequenced by Sanger sequencing. The assignment of analyzed sequences and the determination of sequence types (STs) and clonal complexes (CCs) was done by Bionumerics software (ver. 7.6).

\subsubsection{SCCmec Typing}

The assignment of SCCmec elements was performed using multiplex PCR according to the protocol employed by Milheiriço et al. [47] SCCmec types II and V (untypeable by the aforementioned method) were determined using an alternative set of primers (Supplementary Table S2) according to Zhang et al. [48] DNA sequence of SCCmec type $\mathrm{V}_{\mathrm{T}}$ isolates was amplified using primers for SCCmec type V: Type V-F (5'-GAA CAT TGT TAC TTA AAT GAG CG-3') and Type V-R (5'-TGA AAG TTG TAC CCT TGA CAC C$\left.3^{\prime}\right)$ [48]. PCR product of about $1600 \mathrm{bp}$ was sequenced using Sanger sequencing. Sequence shared $100 \%$ identity with type V staphylococcal cassette chromosome of strain TSGH17 (AB512767.1) [49], which was reported as type $\mathrm{V}_{\mathrm{T}}$ [50]. It was also identical with sequences of other $\mathrm{V}_{\mathrm{T}}$ (VII) strains (AB478780.1, AB462393.1) [49,51].

\section{Conclusions}

To our knowledge, this study has typed (both phenotypically and genotypically) the largest collection of the Czech MRSA isolates from blood cultures so far. In general, MRSA strains were mainly resistant to erythromycin, clindamycin and ciprofloxacin. The majority of the isolates belonged to MLST CC5, with the most prevalent spa types t003, t586, t014 and t002. We have demonstrated that the dominant MRSA clone was ST225/SCCmecII. We confirmed the presence of LA-MRSA within strains grouped in the spa CC011 (CC398) as well as other MRSA clones.

Supplementary Materials: The following are available online at https:/ /www.mdpi.com/article/10 $.3390 /$ antibiotics10040395/s1, Table S1: The characteristics of the 618 MRSA isolates from blood of patients hospitalized in the Czech Republic (2016-2018), Table S2: Primers used in the study.

Author Contributions: Conceptualization, K.P., V.J. and H.Z.; formal analysis, K.P.; investigation, K.P., V.J., L.M., M.F. and M.M.; data curation, K.P. and M.F.; writing—original draft preparation, K.P.; writing-review and editing, V.J., L.M., M.F., M.M. and H.Z.; project administration, H.Z. All authors have read and agreed to the published version of the manuscript.

Funding: This research was funded by Ministry of Health, Czech Republic-conceptual development of research organization the National Institute of Public Health-NIPH, 75010330.

Institutional Review Board Statement: Not applicable.

Informed Consent Statement: Not applicable.

Data Availability Statement: The data presented in this study are available on request from the corresponding author.

Acknowledgments: We thank the Czech EARS-Net participating laboratories for cooperation. We thank Petra Spanelova for her help with the data analysis and Iveta Vrbova, Michaela Horakova and Marketa Cechova for the technical assistance.

Conflicts of Interest: The authors declare no conflict of interest. 


\section{References}

1. Tong, S.Y.C.; Davis, J.S.; Eichenberger, E.; Holland, T.L.; Fowler, V.G. Staphylococcus aureus infections: Epidemiology, pathophysiology, clinical manifestations, and management. Clin. Microbiol. Rev. 2015, 28, 603-661. [CrossRef]

2. European Centre for Disease Prevention and Control. Surveillance of Antimicrobial Resistance in Europe 2016; Annual Report of the European Antimicrobial Resistance Surveillance Network (EARS-Net); ECDC: Stockholm, Sweden, $2017 ;$ p. 54.

3. Grundmann, H.; Schouls, L.M.; Aanensen, D.M.; Pluister, G.N.; Tami, A.; Chlebowicz, M.; Glasner, C.; Sabat, A.J.; Weist, K.; Heuer, O.; et al. The dynamic changes of dominant clones of Staphylococcus aureus causing bloodstream infections in the European region: Results of a second structured survey. Euro Surveill. 2014, 19, 20987. [CrossRef]

4. Surveillance Atlas of Infectious Diseases. Available online: http://atlas.ecdc.europa.eu/public/index.aspx (accessed on 10 April 2020).

5. Melter, O.; Santos Sanches, I.; Schindler, J.; Aires de Sousa, M.; Mato, R.; Kovárova, V.; Zemlicková, H.; Lencastre, H.D. Methicillin-resistant Staphylococcus aureus clonal types in the Czech Republic. J. Clin. Microbiol. 1999, 37, 2798-2803. [CrossRef]

6. Melter, O.; Aires de Sousa, M.; Urbásková, P.; Jakubů, V.; Zemlicková, H.; Lencastre, H.D. Update on the major clonal types of methicillin-resistant Staphylococcus aureus in the Czech Republic. J. Clin. Microbiol. 2003, 41, 4998-5005. [CrossRef]

7. Melter, O.; Urbásková, P.; Jakubů, V.; Macková, B.; Zemlicková, H.; Czech participants in EARSS. Emergence of EMRSA-15 clone in hospitals throughout the Czech Republic. Euro Surveill. 2006, 11, E060803-6. [CrossRef] [PubMed]

8. Grundmann, H.; Aanensen, D.M.; van den Wijngaard, C.C.; Spratt, B.G.; Harmsen, D.; Friedrich, A.W.; European Staphylococcal Reference Laboratory Working Group. Geographic distribution of Staphylococcus aureus causing invasive infections in Europe: A molecular-epidemiological analysis. PLoS Med. 2010, 7, e10000215. [CrossRef]

9. Pomorska, K.; Jakubu, V.; Musilek, M.; Zemlickova, H. Spa typing of methicillin resistant Staphylococcus aureus (MRSA) strains isolated from blood from patients hospitalized in the Czech Republic: A comparative study after ten years. In Proceedings of the 29th Congress of Clinical Microbiology \& Infectious Diseases (ECCMID), Amsterdam, The Netherlands, 13-16 April 2019. Poster no. P2716.

10. Magiorakos, A.P.; Srinivasan, A.; Carey, R.B.; Carmeli, Y.; Falagas, M.E.; Giske, C.G.; Harbarth, S.; Hindler, J.F.; Kahlmeter, G.; Olsson-Liljequist, B.; et al. Multidrug-resistant, extensively drug-resistant and pandrug-resistant bacteria: An international expert proposal for interim standard definitions for acquired resistance. Clin. Microbiol. Infect. 2012, 18, 268-281. [CrossRef] [PubMed]

11. Tkadlec, J.; Capek, V.; Brajerova, M.; Smelikova, E.; Melter, O.; Bergerova, T.; Polivkova, S.; Balejova, M.; Hanslianova, M.; Fackova, D.; et al. The molecular epidemiology of methicillin-resistant Staphylococcus aureus (MRSA) in the Czech Republic. J. Antimicrob. Chemother. 2021, 76, 55-64. [CrossRef] [PubMed]

12. Neradova, K.; Fridrichova, M.; Jakubu, V.; Pomorska, K.; Zemlickova, H. Epidemiological characteristics of methicillin-resistant Staphylococcus aureus isolates from bloodstream cultures at University Hospital in the Czech Republic. Folia Microbiol. 2020, 65, 615-622. [CrossRef]

13. Stock, N.K.; Petráš, P.; Melter, O.; Kapounová, G.; Vopalková, P.; Kubele, J.; Vaniš, V.; Tkadlec, J.; Bukáčková, E.; Machová, I.; et al. Importance of multifaceted approaches in infection control: A practical experience from an outbreak investigation. PLoS ONE 2016, 11, e0157981. [CrossRef] [PubMed]

14. Ridom SpaServer-Frequencies. Available online: https://spa.ridom.de/frequencies.shtml (accessed on 18 December 2020).

15. Strommenger, B.; Kettlitz, C.; Weniger, T.; Harmsen, D.; Friedrich, A.W.; Witte, W. Assignment of Staphylococcus isolates to groups by spa typing, SmaI macrorestriction analysis, and multilocus sequence typing. J. Clin. Microbiol. 2006, 44, 2533-2540. [CrossRef]

16. Aanensen, D.M.; Feil, E.J.; Holden, M.T.G.; Dordel, J.; Yeats, C.A.; Fedosejev, A.; Goater, R.; Castillo-Ramírez, S.; Corander, J.; Colijn, C.; et al. Whole-genome sequencing for routine pathogen surveillance in public health: A Population snapshot of invasive Staphylococcus aureus in Europe. MBio 2016, 7, e00444-16. [CrossRef]

17. Nübel, U.; Dordel, J.; Kurt, K.; Strommenger, B.; Westh, H.; Shukla, S.K.; Zemlicková, H.; Leblois, R.; Wirth, T.; Jombart, T.; et al. A timescale for evolution, population expansion, and spatial spread of an emerging clone of methicillin-resistant Staphylococcus aureus. PLoS Pathog. 2010, 6, e1000855. [CrossRef]

18. Roberts, R.B.; Lencastre, A.D.; Eisner, W.; Severina, E.P.; Shopsin, B.; Kreiswirth, B.N.; Tomasz, A. Molecular epidemiology of methicillin-resistant Staphylococcus aureus in 12 New York hospitals. J. Infect. Dis. 1998, 178, 164-171. [CrossRef] [PubMed]

19. Pardos de la Gandara, M.; Curry, M.; Berger, J.; Burstein, D.; Della-Latta, P.; Kopetz, V.; Quale, J.; Spitzer, E.; Tan, R.; Urban, C.; et al. MRSA causing infections in hospitals in greater metropolitan New York: Major shift in the dominant clonal type between 1996 and 2014. PLoS ONE 2016, 11, e0156924. [CrossRef]

20. Aires de Sousa, M.; Lencastre, H.D.; Santos Sanches, I.; Kikuchi, K.; Totsuka, K.; Tomasz, A. Similarity of antibiotic resistance patterns and molecular typing properties of methicillin-resistant Staphylococcus aureus isolates widely spread in hospitals in New York City and in a hospital in Tokyo, Japan. Microb. Drug. Resist. 2000, 6, 253-258. [CrossRef] [PubMed]

21. Conceição, T.; Aires-de-Sousa, M.; Füzi, M.; Tóth, A.; Pászti, J.; Ungvári, E.; van Leeuwen, W.B.; van Belkum, A.; Grundmann, H.; Lencastre, H.D. Replacement of methicillin-resistant Staphylococcus aureus clones in Hungary over time: A 10-year surveillance study. Clin. Microbiol. Infect. 2007, 13, 971-979. [CrossRef] [PubMed]

22. Aires-de-Sousa, M.; Correia, B.; Lencastre, H.D.; Multilaboratory Project Collaborators. Changing patterns in frequency of recovery of five methicillin-resistant Staphylococcus aureus clones in Portuguese hospitals: Surveillance over a 16-year period. J. Clin. Microbiol. 2008, 46, 2912-2917. [CrossRef] 
23. Zarfel, G.; Luxner, J.; Folli, B.; Leitner, E.; Feierl, G.; Kittinger, C.; Grisold, A. Increase of genetic diversity and clonal replacement of epidemic methicillin-resistant Staphylococcus aureus strains in South-East Austria. FEMS Microbiol. Lett. 2016, 363, fnw137. [CrossRef]

24. Monecke, S.; Coombs, G.; Shore, A.C.; Coleman, D.C.; Akpaka, P.; Borg, M.; Chow, H.; Ip, M.; Jatzwauk, L.; Jonas, D.; et al. A field guide to pandemic, epidemic and sporadic clones of methicillin-resistant Staphylococcus aureus. PLoS ONE 2011, 6, e17936. [CrossRef]

25. Haenni, M.; Châtre, P.; Dupieux-Chabert, C.; Métayer, V.; Bes, M.; Madec, J.Y.; Laurent, F. Molecular epidemiology of methicillinresistant Staphylococcus aureus in horses, cats, and dogs over a 5-year period in France. Front. Microbiol. 2017, 8, 2493. [CrossRef] [PubMed]

26. Tegegne, H.A.; Florianová, M.; Gelbíčová, T.; Karpíšková, R.; Koláčková, I. Detection and molecular characterization of methicillinresistant Staphylococcus aureus isolated from bulk tank milk of cows, sheep, and goats. Foodborne Pathog. Dis. 2019, 16, 68-73. [CrossRef] [PubMed]

27. Tegegne, H.A.; Koláčková, I.; Karpíšková, R. Diversity of livestock associated methicillin-resistant Staphylococcus aureus. Asian Pac. J. Trop. Med. 2017, 10, 929-931. [CrossRef] [PubMed]

28. Neradova, K.; Jakubu, V.; Pomorska, K.; Zemlickova, H. Methicillin-resistant Staphylococcus aureus in veterinary professionals in 2017 in the Czech Republic. BMC Vet. Res. 2020, 16, 4. [CrossRef] [PubMed]

29. Wulf, M.W.; Markestein, A.; van der Linden, F.T.; Voss, A.; Klaassen, C.; Verduin, C.M. First outbreak of methicillin-resistant Staphylococcus aureus ST398 in a Dutch hospital, June 2007. Euro Surveill. 2008, 13, 8051. [CrossRef]

30. O'Neill, G.L.; Murchan, S.; Gil-Setas, A.; Aucken, H.M. Identification and characterization of phage variants of a strain of epidemic methicillin-resistant Staphylococcus aureus (EMRSA-15). J. Clin. Microbiol. 2001, 39, 1540-1548. [CrossRef]

31. Faria, N.A.; Miragaia, M.; Lencastre, H.D.; Multi laboratory project collaborators. Massive dissemination of methicillin resistant Staphylococcus aureus in bloodstream infections in a high MRSA prevalence country: Establishment and diversification of EMRSA-15. Microb. Drug Resist. 2013, 19, 483-490. [CrossRef] [PubMed]

32. Hetem, D.J.; Derde, L.P.G.; Empel, J.; Mroczkowska, A.; Orczykowska-Kotyna, M.; Kozińska, A.; Hryniewicz, W.; Goossens, H.; Bonten, M.J.M.; MOSAR WP3 study group. Molecular epidemiology of MRSA in 13 ICUs from eight European countries. J. Antimicrob. Chemother. 2016, 71, 45-52. [CrossRef]

33. Effelsberg, N.; Stegger, M.; Peitzmann, L.; Altinok, O.; Coombs, G.W.; Pichon, B.; Kearns, A.; Randad, P.R.; Heaney, C.D.; Bletz, S.; et al. Global epidemiology and evolutionary history of Staphylococcus aureus ST45. J. Clin. Microbiol. 2020, 59, e02198-20. [CrossRef]

34. Zemlickova, H.; Fridrichová, M.; Tyllová, K.; Jakubů, V.; Machová, I. Carriage of methicillin-resistant Staphylococcus aureus in veterinary personnel. Epidemiol. Infect. 2009, 137, 1233-1236. [CrossRef]

35. Witte, W.; Werner, G.; Cuny, C. Subtyping of MRSA isolates belonging to a widely disseminated clonal group by polymorphism of the dru sequences in mec-associated DNA. Int. J. Med. Microbiol. 2001, 291, 57-62. [CrossRef] [PubMed]

36. Udo, E.E.; Aly, N.Y.A.; Sarkhoo, E.; Al-Sawan, R.; Al-Asar, A.S.M. Detection and characterization of an ST97-SCCmec-V community-associated meticillin-resistant Staphylococcus aureus clone in a neonatal intensive care unit and special care baby unit. J. Med. Microbiol. 2011, 60, 600-604. [CrossRef] [PubMed]

37. Rubin, I.M.; Hansen, T.A.; Klingenberg, A.M.; Petersen, A.M.; Worning, P.; Westh, H.; Bartels, M.D. A sporadic four-year hospital outbreak of a ST97-IVa MRSA with half of the patients first identified in the community. Front. Microbiol. 2018, 9, 1494. [CrossRef] [PubMed]

38. Idelevich, E.A.; Seifert, H.; Sundqvist, M.; Scudeller, L.; Amit, S.; Balode, A.; Bilozor, A.; Drevinek, P.; Kocak Tufan, Z.; Koraqi, A.; et al. Microbiological diagnostics of bloodstream infections in Europe-an ESGBIES survey. Clin. Microbiol. Infect. 2019, 25, 1399-1407. [CrossRef] [PubMed]

39. European Centre for Disease Prevention and Control. Surveillance of Antimicrobial Resistance in Europe 2018; Annual Report of the European Antimicrobial Resistance Surveillance Network (EARS-Net); ECDC: Stockholm, Sweden, 2019; pp. 56, 73.

40. The European Committee on Antimicrobial Susceptibility Testing. Breakpoint Tables for Interpretation of MICs and Zone Diameters; Version 9.0; EUCAST: Växjö, Sweden, 2019.

41. Clinical and Laboratory Standards Institute (CLSI). Performance Standards for Antimicrobial Susceptibility Testing, 28th ed.; CLSI Supplement M100; Clinical and Laboratory Standards Institute: Wayne, PA, USA, 2018; pp. 136-138.

42. Oliveira, D.C.; Lencastre, H.D. Multiplex PCR strategy for rapid identification of structural types and variants of the mec element in methicillin-resistant Staphylococcus aureus. Antimicrob. Agents Chemother. 2002, 46, 2155-2161. [CrossRef] [PubMed]

43. Stegger, M.; Andersen, P.S.; Kearns, A.; Pichon, B.; Holmes, M.A.; Edwards, G.; Laurent, F.; Teale, C.; Skov, R.; Larsen, A.R. Rapid detection, differentiation and typing of methicillin-resistant Staphylococcus aureus harbouring either mecA or the new mecA homologue mecA(LGA251). Clin. Microbiol. Infect. 2012, 18, 395-400. [CrossRef] [PubMed]

44. Ridom Bioinformatics DNA Sequencing of the Spa Gene. Available online: https://www.ridom.de/doc/Ridom_spa_sequencing. pdf (accessed on 18 December 2020).

45. Ridom StaphType User Guide, Version 2. Available online: https://www.ridom.de/doc/Ridom_StaphType_user_guide.pdf (accessed on 18 December 2020).

46. Enright, M.C.; Day, N.P.; Davies, C.E.; Peacock, S.J.; Spratt, B.G. Multilocus sequence typing for characterization of methicillinresistant and methicillin-susceptible clones of Staphylococcus aureus. J. Clin. Microbiol. 2000, 38, 1008-1015. [CrossRef] 
47. Milheiriço, C.; Oliveira, D.C.; Lencastre, H.D. Update to the multiplex PCR strategy for assignment of mec element types in Staphylococcus aureus. Antimicrob. Agents Chemother. 2007, 51, 3374-3377. [CrossRef]

48. Zhang, K.; McClure, J.A.; Elsayed, S.; Louie, T.; Conly, J.M. Novel multiplex PCR assay for characterization and concomitant subtyping of staphylococcal cassette chromosome mec types I to V in methicillin-resistant Staphylococcus aureus. J. Clin. Microbiol. 2005, 43, 5026-5033. [CrossRef]

49. Hisata, K.; Ito, T.; Matsunaga, N.; Komatsu, M.; Jin, J.; Li, S.; Watanabe, S.; Shimizu, T.; Hiramatsu, K. Dissemination of multiple MRSA clones among community-associated methicillin-resistant Staphylococcus aureus infections from Japanese children with impetigo. J. Infect. Chemother. 2011, 17, 609-621. [CrossRef]

50. Boyle-Vavra, S.; Ereshefsky, B.; Wang, C.C.; Daum, R.S. Successful multiresistant community-associated methicillin-resistant Staphylococcus aureus lineage from Taipei, Taiwan, that carries either the novel staphylococcal chromosome cassette mec (SCCmec) type VT or SCCmec type IV. J. Clin. Microbiol. 2005, 43, 4719-4730. [CrossRef] [PubMed]

51. Takano, T.; Higuchi, W.; Zaraket, H.; Otsuka, T.; Baranovich, T.; Enany, S.; Saito, K.; Isobe, H.; Dohmae, S.; Ozaki, K.; et al. Novel characteristics of community-acquired methicillin-resistant Staphylococcus aureus strains belonging to multilocus sequence type 59 in Taiwan. Antimicrob. Agents Chemother. 2008, 52, 837-845. [CrossRef] [PubMed] 